\title{
A Necessity for MAP Kinase Activation in Mammalian Spatial Learning
}

Joel C. Selcher, ${ }^{1}$ Coleen M. Atkins, ${ }^{1}$ James M. Trzaskos, ${ }^{2}$ Richard Paylor, ${ }^{1,3}$ and J. David Sweatt ${ }^{1,4}$

${ }^{1}$ Division of Neuroscience and

${ }^{2}$ Inflammatory Diseases Research

DuPont Pharmaceuticals Research Laboratories

Wilmington, Delaware 19880 USA

${ }^{3}$ Department of Molecular and Human Genetics

Baylor College of Medicine

Houston, Texas 77030 USA

\begin{abstract}
Although the biochemical mechanisms underlying learning and memory have not yet been fully elucidated, mounting evidence suggests that activation of protein kinases and phosphorylation of their downstream effectors plays a major role. Recent findings in our laboratory have shown a requirement for the mitogen-activated protein kinase (MAPK) cascade in hippocampal synaptic plasticity. Therefore, we used an inhibitor of MAPK activation, SL327, to test the role of the MAPK cascade in hippocampus-dependent learning in mice. SL327, which crosses the blood-brain barrier, was administered intraperitoneally at several concentrations to animals prior to cue and contextual fear conditioning. Administration of SL327 completely blocked contextual fear conditioning and significantly attenuated cue learning when measured $24 \mathrm{hr}$ after training. To determine whether MAPK activation is required for spatial learning, we administered SL327 to mice prior to training in the Morris water maze. Animals treated with SL327 exhibited significant attenuation of water maze learning; they took significantly longer to find a hidden platform compared with vehicle-treated controls and also failed to use a selective search strategy during
\end{abstract}

subsequent probe trials in which the platform was removed. These impairments cannot be attributed to nonspecific effects of the drug during the training phase; no deficit was seen in the visible platform task, and injection of SL327 following training produced no effect on the performance of these mice in the hidden platform task. These findings indicate that the MAPK cascade is required for spatial and contextual learning in mice.

\section{Introduction}

One of the most intriguing and intensely studied questions facing contemporary neuroscientists involves the elucidation of the physiological mechanisms that underlie learning and memory. Two paradigms that have been used extensively in studying learning are the conditioned fear task (LeDoux 1995) and the Morris water task (Morris 1981). In fear conditioning, animals learn to associate neutral stimuli with an aversive one, such as a foot shock. In the spatial learning version of the Morris water task, animals learn to locate a hidden escape platform in a pool of water using various distal visual cues. Hippocampal lesions have been shown to produce learning deficits in variants of both of these tasks in mice (Logue et al. 1997).

Although evidence from studies of hippocampal synaptic plasticity and of the behaving animal suggest that activation of protein kinases may contribute to the formation of memories (Silva et al. 1992; Abeliovich et al. 1993; Atkins et al. 1998; Berman et al. 1998), the underlying signal trans-

${ }^{4}$ Corresponding author.

LEARNING \& MEMORY 6:478-490 @ 1999 by Cold Spring Harbor Laboratory Press ISSN1072-0502/99 \$5.00

$$
\begin{array}{llllllllllllllllll}
\mathbf{4} & E & A & R & N & I & N & G & \mathbf{Z} & M & E & M & O & R & Y
\end{array}
$$


duction mechanisms remain largely unknown. We observed previously that activation of the mitogenactivated protein kinase (MAPK) cascade is required both in the induction of a long-lasting form of hippocampal synaptic plasticity (English and Sweatt 1997) and in associative learning in the rat (Atkins et al. 1998). In the first study, a high-frequency stimulation paradigm that reliably produces robust long-term potentiation (LTP) was delivered to Schaffer collateral inputs to area CA1 of the hippocampus. This stimulation activated the $\mathrm{p} 42$ isoform, but not the $\mathrm{p} 44$ isoform of MAPK. In addition, pretreatment of hippocampal slices with an inhibitor of MAPK activation significantly attenuated the induction of LTP. The p42 isoform of MAPK was also activated following training with a fear-conditioning protocol. Inhibition of MAPK activation in rats abolished both contextual and cue learning. To extend these findings, we investigated the contribution of the MAPK cascade to spatial learning.

The MAPK cascade has been studied extensively in the context of cell proliferation and differentiation. The classic cascade consists of at least three protein kinases beginning with the serine/ threonine kinases Raf-1 or B-Raf. Phosphorylation by either of these kinases leads to activation of the MAP kinase kinase (MEK). MEK, in turn, is a dedicated dual-specificity kinase that phosphorylates and thereby activates only MAPK (Seger and Krebs 1995). To investigate the role of MAPK activation in the nervous system, we have previously used a selective inhibitor of MEK, SL327 (Atkins et al. 1998; Favata et al. 1998). SL327 is active in the central nervous system when administered peripherally, and selectively blocks activation of MAPK by MEK. In the present study, we used this inhibitor to investigate the role of MAPK activation in conditioned fear and spatial learning in mice.

\section{Materials and Methods}

\section{SUBJECTS}

Adult male 129S3/SvImJ mice (formerly 129/

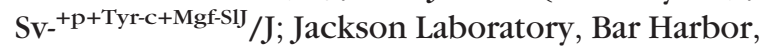
ME) were used in all experiments. Animals were housed on a $12 \mathrm{hr}$-light/dark schedule. All experiments were performed in accordance with the Baylor College of Medicine Institutional Animal Care and Use Committee and with national regulations and policies.

\section{SAMPLE PREPARATION}

Animals were injected intraperitoneally (i.p.) with either SL327 (2 ml/kg, dissolved in 100\% DMSO) or vehicle ( $2 \mathrm{ml} / \mathrm{kg}, 100 \% \mathrm{DMSO})$. In the time course study, animals were sacrificed at various time points after injection $(0,30,60,80,100$, 120 , or $180 \mathrm{~min}$ post-injection). The brains were immediately removed and perfused with ice-cold saline (125 mm NaCl, $2.5 \mathrm{~mm} \mathrm{KCl,} 1.25 \mathrm{~mm} \mathrm{NaH}_{2} \mathrm{PO}_{4}, 25$ $\mathrm{mm} \mathrm{NaHCO}_{3}, 25 \mathrm{~mm}$ D-glucose, $2 \mathrm{~mm} \mathrm{CaCl}_{2}, 1 \mathrm{~mm}$ $\mathrm{MgCl}_{2}$, saturated with $95 \% \mathrm{O}_{2} / 5 \% \mathrm{CO}_{2}$ at $\mathrm{pH} 7.4$ ). Hippocampi were dissected, then homogenized in $2 \mathrm{ml}$ of buffer (20 mm Tris- $\mathrm{HCl}$ at $\mathrm{pH} \mathrm{7.5,} 1 \mathrm{~mm}$ EGTA, $1 \mathrm{~mm}$ EDTA, $25 \mu \mathrm{g} / \mathrm{ml}$ aprotonin, $25 \mu \mathrm{g} / \mathrm{ml}$ leupeptin, $1 \mathrm{~mm} \mathrm{Na} \mathrm{P}_{2} \mathrm{O}_{7}, 500 \mu \mathrm{M}$ PMSF, $4 \mathrm{~mm}$ paranitrophenylphosphate, $1 \mathrm{~mm}$ sodium orthovanadate). Sample buffer containing SDS and $\beta$-mercaptoethanol was immediately added to the homogenate, and the samples were boiled at $95^{\circ} \mathrm{C}$ for 10 min. Samples were electrophoresed on a $10 \%$ SDSpolyacrylamide gel, blotted electrophoretically to Immobilon-P, and blocked in TTBS buffer (50 mM Tris- $\mathrm{HCl}$ at $\mathrm{pH}$ 7.5, $150 \mathrm{~mm} \mathrm{NaCl}, 0.05 \%$ Tween-20). Western blots were blocked in TTBS with 3\% BSA. The following primary antibodies were used: activated MAPK (1:1000; New England Biolabs, Beverly, MA) and total MAPK (1:3000; UBI, Baltimore, MD). All blots were incubated with a secondary antibody conjugated to horseradish peroxidase (1: 30,000) and developed by the enhanced chemiluminescence method (Amersham, Piscataway, NJ). To assess for changes in the activation of MAPK, phosphorylation levels were normalized relative to the corresponding total MAPK amount. The density of each band was quantified by a StudioScan desktop scanner with NIH Image software. Western blots were developed to be linear in the range used for densitometry. DuPont Pharmaceuticals Research Laboratories generously provided SL327, a structural analogue of U0126.

\section{PROTEIN KINASE ASSAYS}

Protein kinase assays were performed as described in Chen et al. (1993). All kinase assays were started by adding enzyme to a mixture that included $\left[\gamma^{-32} \mathrm{P}\right]$ ATP (Amersham) and substrate. This mixture was then incubated at $30^{\circ}$ or $37^{\circ} \mathrm{C}$ for 10 $\min$. The reaction was stopped by spotting aliquots of the reaction mixture onto Whatman P-81 phosphocellulose filter paper. The papers were then washed in $150 \mathrm{~mm} \mathrm{H}_{3} \mathrm{PO}_{4}$, dried, and subjected to

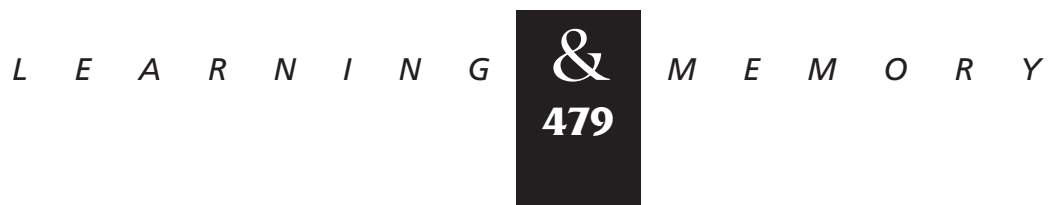




\section{Selcher et al.}

scintillation counting. The catalytic subunit of PKA was assayed by measuring $\left[{ }^{32} \mathrm{P}\right]$ phosphate incorporation into the substrate Kemptide $(100 \mu \mathrm{M})$. The activity of CaMKII was determined by measuring phosphorylation of the synthetic peptide Autocamtide $(100 \mu \mathrm{M})$ in the presence of $100 \mu \mathrm{M}$ calcium and $10 \mu \mathrm{g} / \mathrm{ml}$ calmodulin. A synthetic peptide analog of a fragment of neurogranin, $\mathrm{NG}_{(28-43)}$ (10 $\mu \mathrm{m}$; Chen et al. 1993) was used as a specific substrate for the catalytic subunit of PKC. In all cases, substrate phosphorylation was linear with respect to time and enzyme concentration.

\section{FEAR CONDITIONING}

In the $1 \times$-pairing paradigm of cue and contextual fear conditioning, animals were placed in the fear conditioning apparatus for $3 \mathrm{~min}$, then a 30sec acoustic conditioned stimulus (CS; white noise, $80 \mathrm{~dB}$ ) was delivered. During the last second of the CS, a 1-sec shock unconditioned stimulus (US; 0.5 $\mathrm{mA}$ ) was applied to the grid floor. To assess contextual learning, the animals were returned to the training context $24 \mathrm{hr}$ post-training, and freezing behavior was scored for $5 \mathrm{~min}$. To assess cue learning, the animals were placed in a different context (novel odor, lighting, cage floor, and visual cues) following contextual testing. Baseline behavior was measured for $3 \mathrm{~min}$ in the novel context (PreCS), then the tone was presented for $3 \mathrm{~min}$. Freezing behavior was assessed with a time sampling procedure whereby the animal was observed for $\sim 1 \mathrm{sec}$ every $5 \mathrm{sec}$. The experimenter was blind to drug treatment. Animals were injected with either vehicle ( $2 \mathrm{ml} / \mathrm{kg}, 100 \% \mathrm{DMSO})$ or SL327 (10, 30, and $50 \mathrm{mg} / \mathrm{kg}$; at $2 \mathrm{ml} / \mathrm{kg}$, dissolved in $100 \%$ DMSO) intraperitoneally $1 \mathrm{hr}$ before training.

For the 3x-pairing paradigm, 20-sec acoustic CS-US pairings were given three times. There was a 60-sec interval between each CS-US pairing. All other aspects of this protocol were the same as in the $1 \mathrm{x}$-pairing paradigm.

\section{MORRIS WATER MAZE}

Naïve mice (8-10-weeks old) were trained in the Morris water task to locate a hidden escape platform in a circular pool (1.38 $\mathrm{m}$ Nalge pool) of opaque water with distal visual cues outside of the pool. Mice were injected $30 \mathrm{~min}$ before training with either $30 \mathrm{mg} / \mathrm{kg} \mathrm{SL} 327$ ( $2 \mathrm{ml} / \mathrm{kg}$ ) or vehicle (2 $\mathrm{ml} / \mathrm{kg} ; 100 \%$ DMSO). Each mouse was given two blocks of four trials a day for 5 consecutive days. Subjects were released into the pool from one of four starting positions, and the location of the platform remained constant throughout training. Time to find the escape platform (escape latency) was measured. Following blocks 8 and 10, probe tests were given. In the probe test, the platform was removed and animals were allowed to search the pool for $60 \mathrm{sec}$. Quadrant search time and platform crossings were assessed to characterize a subject's search behavior during the probe trial. The quadrant search measure was obtained by dividing the pool into four equal quadrants, then measuring the amount of time that the subject spent searching in each quadrant. The platform crossing measure was the number of times a subject crossed the exact place where the platform had been located during training. For comparison, the number of times a subject crossed the equivalent location in the other quadrants was determined. Data from the two probe trials were averaged. On the sixth day, animals that had been administered vehicle for the first 5 days were now injected with SL327 and the animals treated previously with SL327 were injected with vehicle. Two more blocks of training were given followed by another probe trial.

Another set of vehicle- and SL327-treated mice were trained on the visible platform task. In this test, animals were required to locate a platform whose position was marked by a post extending 10 $\mathrm{cm}$ out of the water, topped by a large black cube $\left(\sim 450 \mathrm{~cm}^{3}\right)$. The location of the platform remained constant throughout training. Training consisted of two blocks of four trials a day for 3 consecutive days. Escape latencies were determined for each trial and probe tests were given following blocks 4 and 6 on days 2 and 3 , respectively.

\section{Results}

MAPK ACTIVATION IS BLOCKED BY SL327 IN VIVO

We observed previously that $100 \mathrm{mg} / \mathrm{kg}$ SL327 crosses the blood-brain barrier in rats and effectively attenuates basal levels of activated MAPK in the rat central nervous system (Atkins et al. 1998). To begin this study, we determined the most effective dosage of SL327 for peripheral administration in mice.

Mice were injected with various concentrations of SL327 (10, 30, $50 \mathrm{mg} / \mathrm{kg}$ i.p.), and $1 \mathrm{hr}$ later their hippocampi were removed and assayed for activated MAPK (Fig. 1A). Using an antibody

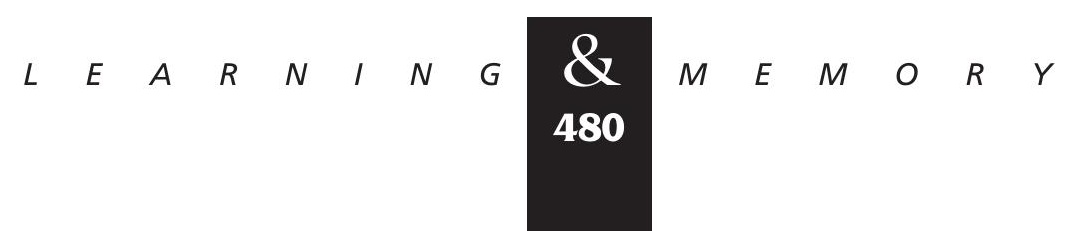


A
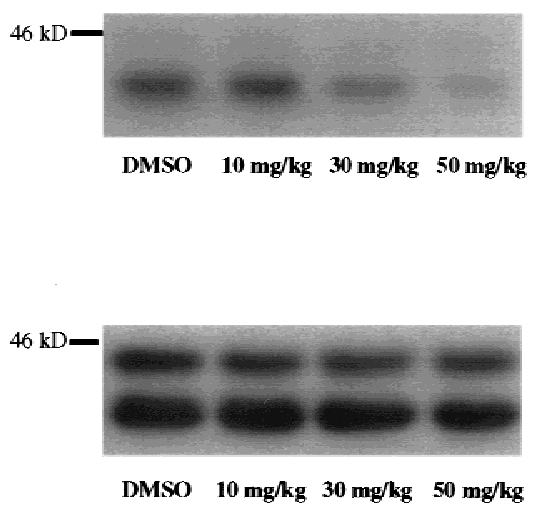

Anti-phosphoMAPK

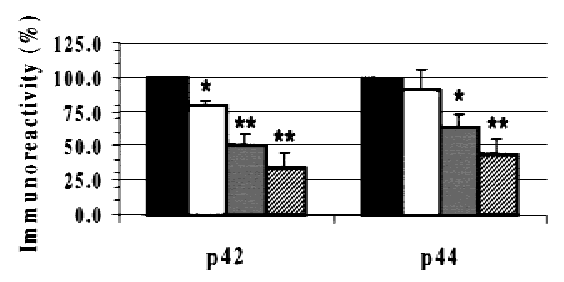

Anti-MAPK

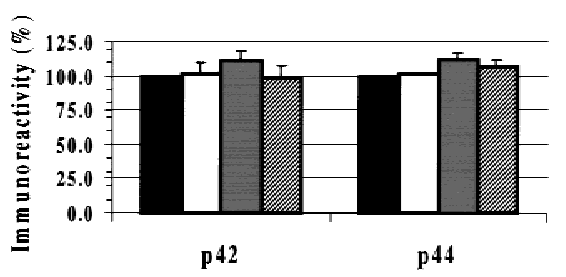

B

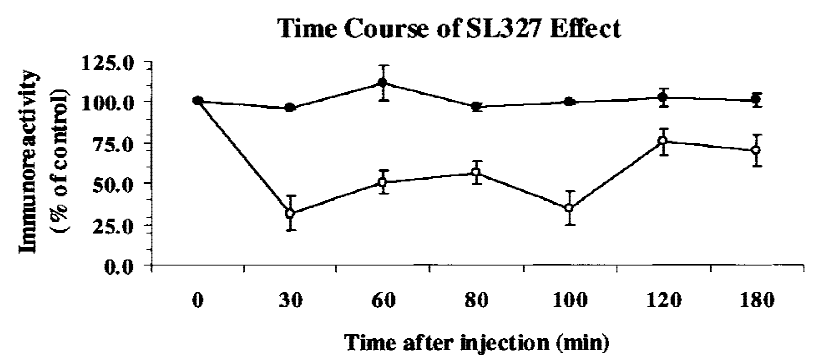

Figure 1: SL327 inhibits MAPK activation in the hippocampus. (A) Both p42 and p44 phospho-MAPK levels were significantly inhibited 60 min after injection with 30 or $50 \mathrm{mg} / \mathrm{kg}$ SL327. There was no concurrent decrease in total MAPK levels for either isoform with any concentration of SL327 tested. (black bar) DMSO; (white bar) $10 \mathrm{mg} / \mathrm{kg}$; (gray bar) 30 $\mathrm{mg} / \mathrm{kg}$; (hatched bar) $50 \mathrm{mg} / \mathrm{kg}$. (B) The time course of the effect of SL327 is shown. The level of phosphorylated MAPK decreased $30 \mathrm{~min}$ after SL327 injection and remained below baseline levels for at least $3 \mathrm{hr}$. [(O)] p42 (phospho MAPK; $[(\mathbf{O})]$ p42 (total MAPK). There was no change in the level of total MAPK during the $3 \mathrm{hr}$ following drug injection. For all figures, data represents mean \pm S.E.M.. ${ }^{(*)} P<0.01 ;(*) P<0.05$.

for dually phosphorylated and thus activated MAPK, we observed greater basal phosphorylation of the p42 isoform than the p44 isoform in the hippocampus, as we have observed previously in rats (English and Sweatt 1996, 1997; Atkins et al. 1998). SL327 attenuated phosphorylated MAPK levels in a dose-dependent manner. Administration of 10,30 , or $50 \mathrm{mg} / \mathrm{kg}$ SL327 significantly attenuated p42 phospho-MAPK levels $(F=20.90$, $P<0.0001$; Newman Keuls post hoc comparison, $10 \mathrm{mg} / \mathrm{kg}$ SL327 vs. vehicle, $P<0.05$, and 30 and $50 \mathrm{mg} / \mathrm{kg} \mathrm{SL327}$ vs. vehicle, $P<0.001)$. Injection with 30 or $50 \mathrm{mg} / \mathrm{kg}$ SL327 also significantly reduced p44 phospho-MAPK levels $(F=5.627$, $P<0.005$; Newman-Keuls post hoc comparison, $30 \mathrm{mg} / \mathrm{kg}$ vs. vehicle, $P<0.05$, and $50 \mathrm{mg} / \mathrm{kg}$ SL327 vs. vehicle, $P<0.01)$. There was no concurrent decrease in total MAPK levels with either of these drug concentrations. These results indicate that 10,30 , and $50 \mathrm{mg} / \mathrm{kg} \mathrm{SL327}$ injected intraperitoneally can cross the blood-brain barrier in the mouse at concentrations sufficient to block MAPK activation in vivo.

Next, we determined the time course of the drug's effect on MAPK activation. Following injection with $30 \mathrm{mg} / \mathrm{kg}$ SL327, mice were sacrificed at various time points and their hippocampi were assayed for activated MAPK. Thirty minutes after the injection, activated MAPK levels for both the p42 (Fig. 1B) and the p44 (data not shown) isoforms were lower than baseline measurements taken from mice sacrificed immediately after injection. Phospho-MAPK in the hippocampus remained at this low level until 100 min post-injection, whereafter levels began to rise slightly. Activated kinase levels were, however, still reduced compared with

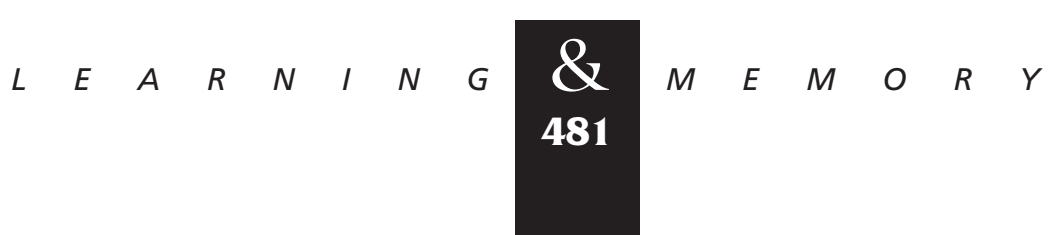


baseline $3 \mathrm{hr}$ after injection, the latest time point tested. There was no change in the level of total MAPK for either isoform during the $3 \mathrm{hr}$ following drug injection (Fig. 1B). These results suggest that SL327 is most effective in blocking MAPK activation between $30 \mathrm{~min}$ and $2 \mathrm{hr}$ after injection. All of the training in the behavioral studies therefore took place during this time window.

\section{KINASE INHIBITION BY SL327 IS SPECIFIC TO MAPK}

For the results of these studies to selectively implicate the MAPK cascade in learning, the specificity of SL327 for MEK was investigated. Prior results implicate cAMP-dependent protein kinase (PKA), calcium/calmodulin-dependent protein kinase II (CaMKII), and protein kinase C (PKC) in hippocampus-dependent learning (Silva et al. 1992; Abeliovich et al. 1993; Bourtchuladze et al. 1994; Wolfman et al. 1994; Nogues et al. 1996; Paylor et al. 1996; Mansuy et al. 1998). We tested whether SL327 could inhibit these other kinases. Kinase activity was assessed by measuring the incorporation of $\left[{ }^{32} \mathrm{P}\right]$ phosphate during phosphorylation of substrate peptides specific for each kinase. Although SL327 inhibits MEK with an $\mathrm{IC}_{50}$ of $0.27 \mu \mathrm{M}$ (J.M. Trazskos, pers. comm.), $10 \mu \mathrm{M}$ SL327 had no significant effect on PKA (control $=8.76 \pm 1.71 \quad \mathrm{pmole} / \mathrm{min}, \quad 10 \mu \mathrm{M}$ SL327 $=8.37 \pm 0.71 \quad \mathrm{pmole} / \mathrm{min} ; \quad F=0.053$, $P>0.05$ ), CaMKII (control $=8.52 \pm 0.77$ pmole/ $\min , \quad 10 \mu \mathrm{M} \quad \mathrm{SL} 327=7.39 \pm 0.37 \mathrm{pmole} / \mathrm{min}$; $F=1.251, P>0.05$ ), or PKC (control $=1.31 \pm 0.33$ $\mathrm{pmole} / \mathrm{min}, 10 \mu \mathrm{M}$ SL327 $=1.15 \pm 0.20$ pmole $/$ $\min ; F=0.02, P>0.05)$. These results suggest that effects of the drug are not due to inhibition of PKA, PKC, or CaMKII.

\section{SL327 BLOCKS CONTEXTUAL FEAR CONDITIONING AND ATTENUATES CUE LEARNING}

Next, we investigated whether MAPK activation is necessary for fear conditioning in the mouse. SL327 was administered intraperitoneally at several concentrations to subjects $1 \mathrm{hr}$ prior to cue and contextual fear conditioning. For these experiments, an aversive stimulus (in this case, a mild foot shock) was paired either once or three times with an auditory CS within a novel environment. When tested $24 \mathrm{hr}$ after training, control mice exhibited marked fear, measured by freezing behav- ior, in response to re-presentation of either the context or the auditory CS delivered in a different context.

Compared with vehicle, administration of SL327 before training with the single pairing protocol altered both contextual and cue conditioning in a dose-dependent manner. Injection with either $10 \mathrm{mg} / \mathrm{kg}$ or $30 \mathrm{mg} / \mathrm{kg} \mathrm{SL327}$ prior to one pairing of CS and shock completely blocked contextual learning ( $F=8.491, P<0.005$; Newman-Keuls post hoc comparison, both SL327 concentrations less than vehicle, $P<0.01$ ) (Fig. $2 \mathrm{~B}$, left). By use of the $1 \times$-pairing paradigm, cue learning was also attenuated by either $10 \mathrm{mg} / \mathrm{kg}$ or $30 \mathrm{mg} / \mathrm{kg}$ SL327 ( $F=8.342, \quad P<0.005 ; \quad$ Newman-Keuls post hoc comparison, $10 \mathrm{mg} / \mathrm{kg} \mathrm{SL} 327$ vs. vehicle, $P<0.05$, and $30 \mathrm{mg} / \mathrm{kg} \mathrm{SL} 327$ vs. vehicle, $P<0.01$ ) (Fig. $2 \mathrm{~B}$, right).

When a more intense training protocol was used, SL327 only impaired contextual learning. Following three CS-US pairings, both $10 \mathrm{mg} / \mathrm{kg}$ and 30 $\mathrm{mg} / \mathrm{kg}$ SL327 significantly attenuated freezing in response to the context $(F=7.438, P<0.005$; Newman-Keuls post hoc comparison, $10 \mathrm{mg} / \mathrm{kg}$ SL327 vs. vehicle, $P<0.05$, and $30 \mathrm{mg} / \mathrm{kg} \mathrm{SL} 327$ vs. vehicle, $P<0.01$ ) (Fig. $2 \mathrm{C}$, left). There was no significant difference in freezing between animals treated with vehicle, 10 , and $30 \mathrm{mg} / \mathrm{kg}$ SL327 in response to the cue delivered in a different context $(F=1.882, P>0.05)$ (Fig. 2C, right).

To assess baseline behavior, we monitored the activity of SL327-treated animals during the training phase. SL327 produced no effect on baseline freezing behavior prior to presentation of the foot shock on the training day (minutes $1-3$ in Fig. 2A; $P>0.05$ ). There was also no difference in pain sensitivity as measured by freezing on the training day in response to one application of the foot shock (minutes $4-6$ in Fig. $2 \mathrm{~A} ; P>0.05$ ). Thus, inhibition of learning by SL327 did not result from a change in foot shock sensitivity.

We observed that higher doses of SL327 (50, 75 , and $100 \mathrm{mg} / \mathrm{kg}$ ) tended to affect freezing behavior prior to the foot shock (data not shown). Therefore, for the remainder of the study, $30 \mathrm{mg} /$ $\mathrm{kg}$ was the highest concentration of SL327 tested.

As an additional test of the effects of MEK inhibition on general activity levels and to test for anxiolytic effects of the drug, animals were monitored by the open-field test. With this test, we observed that $30 \mathrm{mg} / \mathrm{kg} \mathrm{SL327}$ had no effect on general activity levels $(P>0.05)$, evaluated by measurements of horizontal activity, vertical activity, and

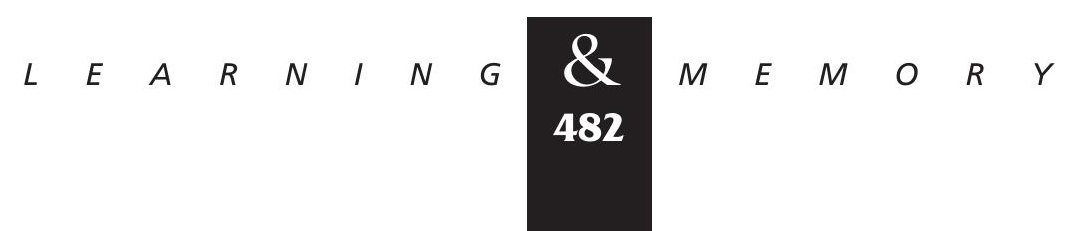



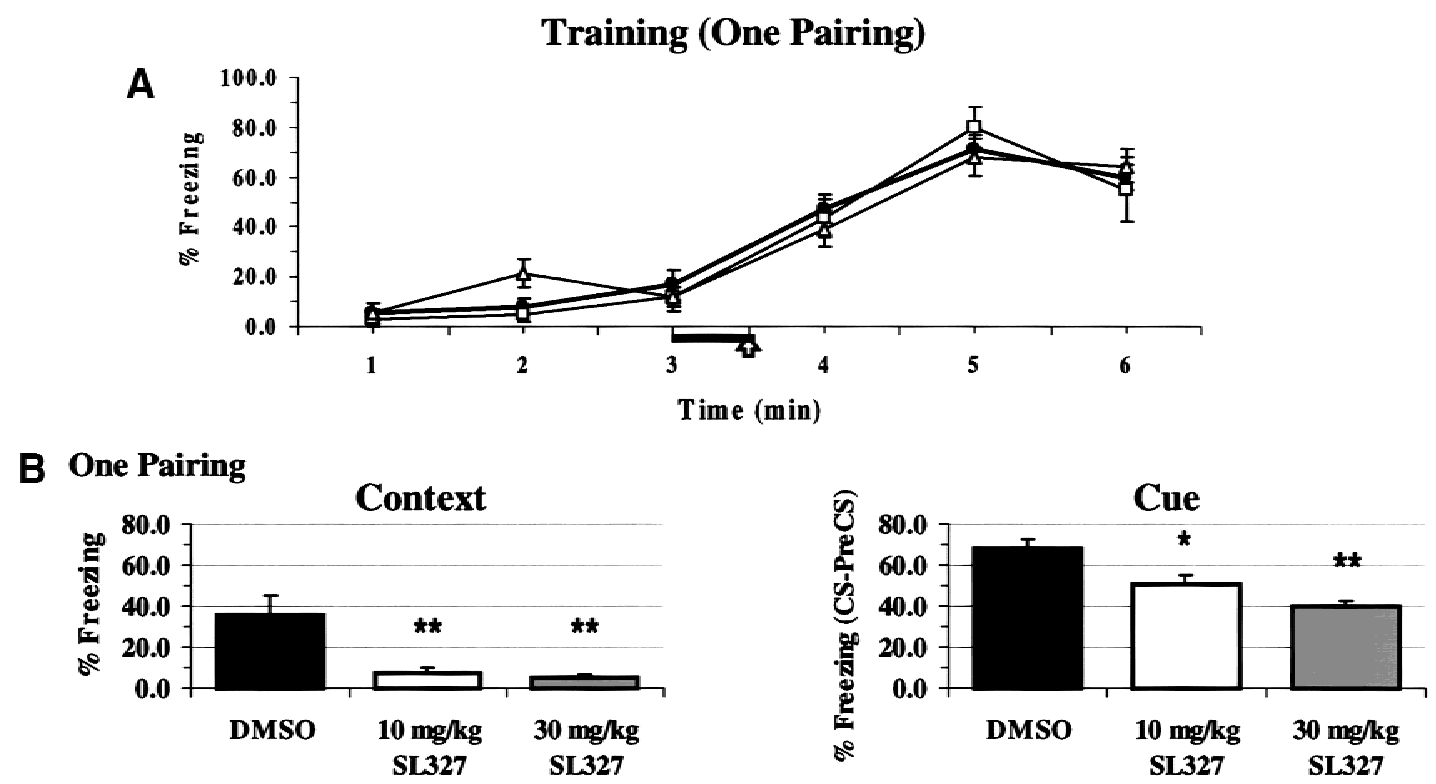

\section{Three Pairings}
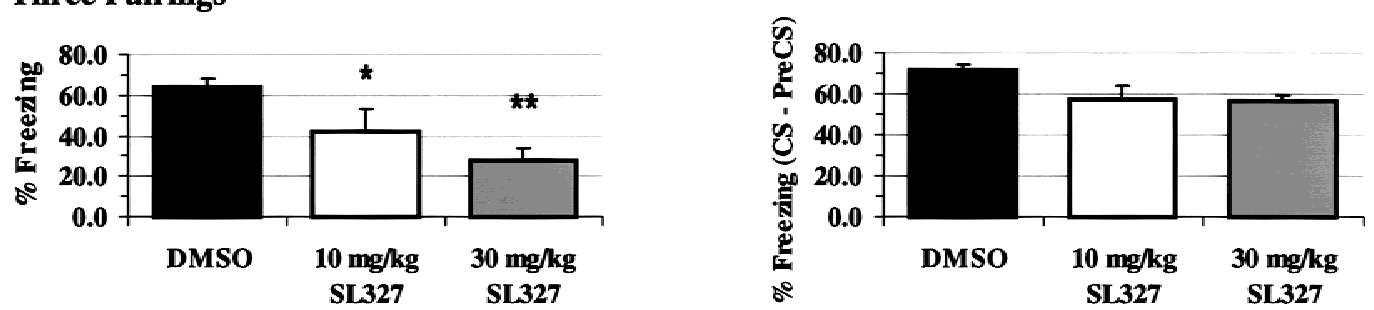

Figure 2: Administration of SL327 during training blocks contextual fear conditioning and significantly attenuates cue learning in a dose-dependent manner. $(A)$ Freezing responses during the training phase are shown. A tone (solid bar) was paired with a foot shock (arrow) between minutes 3 and 4. (○) DMSO; ( $\square) 10 \mathrm{mg} / \mathrm{kg} \mathrm{SL327;} \triangle$ ) $30 \mathrm{mg} / \mathrm{kg}$ SL327. Baseline behavior (before presentation of the tone) and shock response (after the foot shock) were similar for all groups. ( $B$ ) Mice given SL327 (10 mg/kg, $n=5$ or $30 \mathrm{mg} / \mathrm{kg}, n=7)$ showed significant reductions in freezing to the context $24 \mathrm{hr}$ after receiving one pairing of tone and shock as compared with animals injected with vehicle $(n=6)$, left. Administration of 10 or $30 \mathrm{mg} / \mathrm{kg}$ SL327 was also sufficient to significantly attenuate freezing to the cue (CS-PreCS), right. (C) When animals were trained with three pairings of tone and foot shock, $10 \mathrm{mg} / \mathrm{kg}$ and $30 \mathrm{mg} / \mathrm{kg} \mathrm{SL327} \mathrm{(10} \mathrm{mg/kg,} n=6 \mathrm{or} 30 \mathrm{mg} / \mathrm{kg}$, $n=7)$ blocked freezing to the context compared with vehicle $(n=10)$, left. The additional pairings of tone and shock eliminated any effect of SL327 on freezing in response to the cue, right. There was no difference between the PreCS values for any of the groups with either the $1 \times$ or $3 \times$ paradigms. $(* *) P<0.01 ;\left({ }^{*}\right) P<0.05$.

total distance traveled during the 10 min test session. The open field test also measures anxiety levels, as assessed by the center distance to total distance ratio. Injection with $30 \mathrm{mg} / \mathrm{kg}$ SL327 produced no anxiolytic effects in these mice $(P>0.05)$. These results suggest that the baseline behavior of mice was not altered by treatment with $30 \mathrm{mg} / \mathrm{kg} \mathrm{SL327.}$

\section{SL327 IMPAIRS SPATIAL LEARNING}

Having observed that activation of the MAPK cascade is necessary for the hippocampus-depen- dent associative learning task, contextual fear conditioning, we investigated a role for the MAPK cascade in spatial learning. We tested the effect of SL327 on performance in the Morris water maze, a hippocampus-dependent spatial learning task in which mice are required to learn to locate an escape platform in a pool of water using visual cues surrounding the maze (Morris 1981). Mice were administered $30 \mathrm{mg} / \mathrm{kg}$ SL327 30 min before training in the water maze. Training consisted of two blocks of four trials a day with an interblock interval of $\sim 1 \mathrm{hr}$. The training was given for 6 consecutive days in the hidden platform version of the task

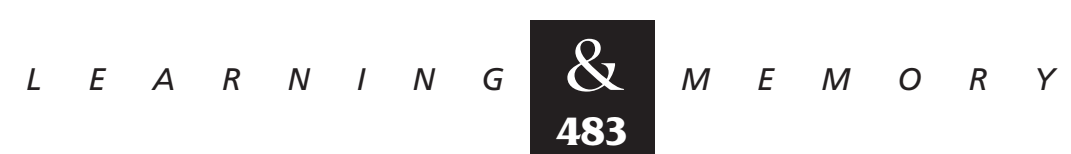




\section{Selcher et al.}

and for 3 consecutive days in the visible platform version. We chose $30 \mathrm{mg} / \mathrm{kg} \mathrm{SL327}$ on the basis of the efficacy of this dosage in blocking MAPK activation in vivo and the lack of nonspecific effects in the fear conditioning paradigm.

In the hidden-platform version of the Morris water maze task, mice injected with vehicle displayed significant improvement in their performance over the 10 blocks of training trials $(F=4.4$, $P<0.0001$ ) (Fig. 3A), whereas SL327-treated mice showed impairments in escape latency. SL327treated mice took significantly longer to locate the escape platform than did control mice $(F=33.19$, $P<0.0001)$.

To determine whether animals were using a spatial learning strategy to locate the escape platform, the mice were subjected to probe trials after training on days 4 and 5 (Fig. 4A). Vehicle-treated mice spent significantly more time searching in the trained quadrant than in each of the other three quadrants $(F=7.159, \quad P<0.001 ; \quad$ Newman-Keuls post hoc comparisons, trained more than all other quadrants, $P<0.01$ ). They also crossed the place where the platform had been located during training significantly more often than the correspond- ing place in the other quadrants $(F=13.82$, $P<0.0001$; Newman-Keuls post hoc comparison, trained more than all other quadrants, $P<0.001$ ). Thus, vehicle-treated mice selectively searched in the correct quadrant. However, SL327-treated animals did not spend significantly more time in the trained quadrant than the other quadrants $(F=0.406, P>0.05)$. They also did not cross the platform region in the trained quadrant more often than equivalent sites in the other quadrants $(F=1.769, P>0.05)$. Therefore, SL327 prevents the development of a selective search strategy. Representative traces for both vehicle- and SL327treated mice are shown in Figure 5, illustrating the lack of a selective search in SL327-treated mice. Overall, these results suggest that blocking MAPK activation impairs performance on a spatial learning task.

As a test to determine whether SL327 was actually impairing learning rather than merely interfering with execution of the task, the drug and control groups were reversed on day 6: Animals that had been administered vehicle for the first 5 days were now injected with SL327, and SL327treated animals were given the vehicle. If the drug
Figure 3: Injection of SL327 produces significantly longer escape latencies in the hidden platform version, but not the visible platform version of the Morris water maze task. (A) Average escape latency during training on the hidden platform task. Performance for mice injected with vehicle $(n=13)$ improved over the course of the training. SL327-treated mice $(n=11)$ took significantly longer to locate the escape platform. The dark vertical line between blocks 10 and 11 represents the drug switch on day 6 . On that day, SL327trained mice $(\triangle)$ received DMSO $(n=9)$, whereas DMSO-trained animals $(\mathbf{O})$ received SL327 $(n=11)$. (B) Average escape latency during training on the visible platform task. Performance for both mice treated with SL327 $(n=5)$ and those treated with vehicle $(n=5)$ improved during training and there was no significant difference between the two groups. Although it is not necessary for the performance of the task, rats trained on the fixed visible platform task develop a cognitive map of the platform's location in relation to the visual cues outside the pool ( $R$. Paylor, unpubl.). When the platform is removed and a probe test is given, these animals display a selective search strategy. Because we trained our mice using a fixed visible platform paradigm, we investigated whether these animals also passively acquired this spatial information. Neither SL327-treated nor vehicle-treated animals searched for the platform selectively during probe tests given after training on days 2 and 3 (data not shown).(O) Control; (A) SL327.

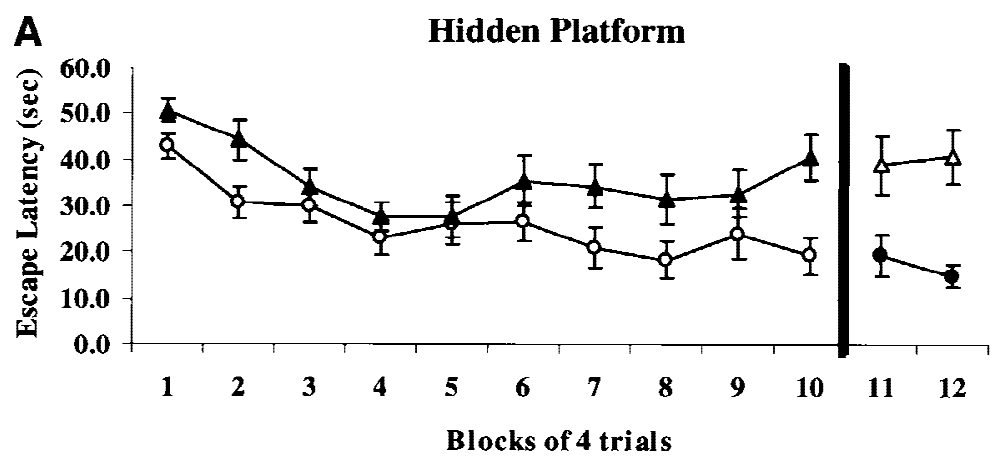

B

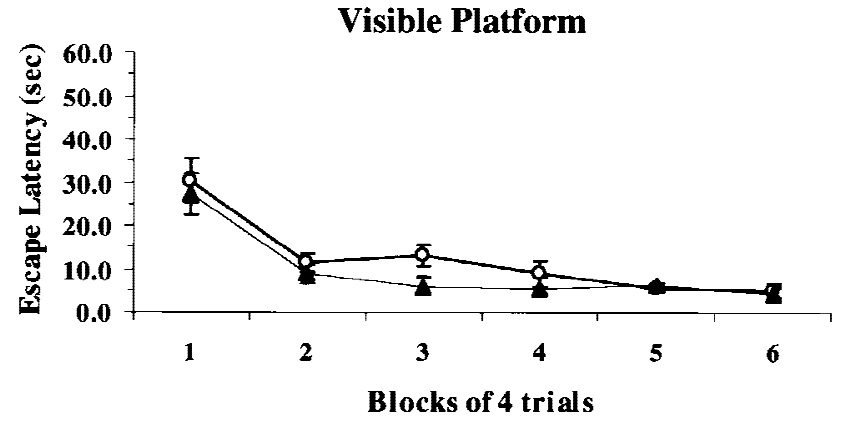




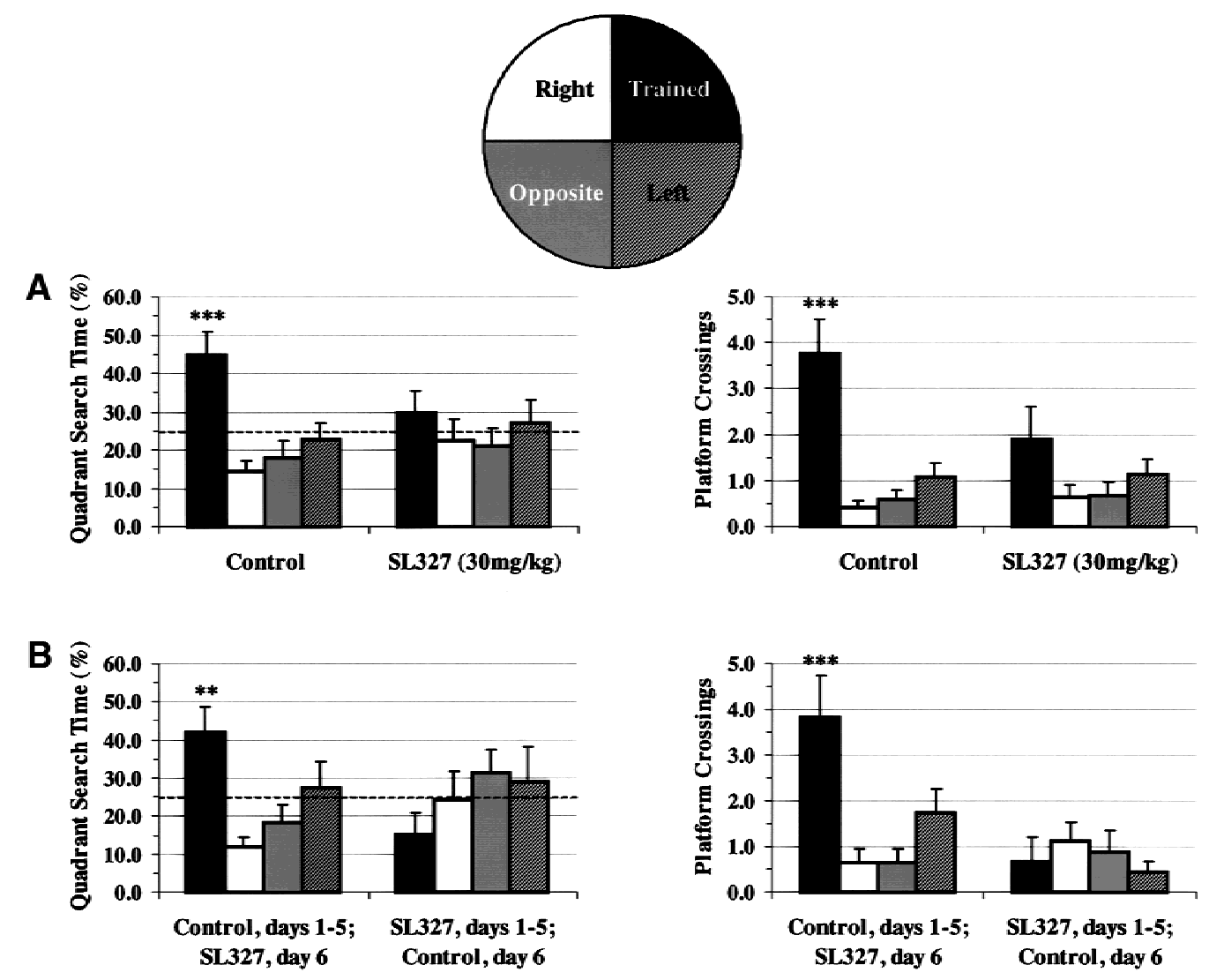

Figure 4: Administration of SL327 significantly impaired spatial learning performance in the Morris water maze task. $(A)$ During the probe trials on days 4 and 5 , mice treated with vehicle $(n=13)$ spent significantly more time searching in the trained quadrant and crossed the platform area in the trained quadrant more frequently than in any of the alternate quadrants. However, mice injected with $30 \mathrm{mg} / \mathrm{kg}$ SL327 $(n=11)$ did not exhibit a selective search strategy. There was no significant difference between the time spent in the trained quadrant and platform crossings as compared with the other quadrants. $(B)$ The drug treatment was switched on day 6; animals who had received SL327 during the first 5 days now received vehicle and vice versa. The vehicle-trained mice $(n=11)$ still exhibited a selective search strategy after injection with SL327 on day 6. SL327-trained mice $(n=9)$ who were administered vehicle on day 6 , did not display a selective search strategy. $(* * *)$ Significantly larger $(P<0.01)$ than all three of the other quadrants.

was altering the perceptual or motor abilities of the animals, administration of SL327 on day 6 should impair the performance of vehicle-trained mice. The performance of mice trained with vehicle did not deteriorate after injection of SL327 on day 6 (Fig. 3A). In addition, mice trained with SL327, but injected with vehicle on day 6 still performed significantly worse than vehicle-trained animals with respect to escape latency (Fig. 3A).

A probe test was also given following the training session on day 6 to test the effect of SL327 on general cognitive abilities. Again, if the drug was having effects nonspecific to learning, control animals given SL327 might no longer search selectively for the escape platform. Animals receiving vehicle on days 1-5 and SL327 on day 6 still uti- lized a selective strategy in searching for the missing platform as measured by quadrant search time ( $F=4.496, P<0.05$; Newman-Keuls post hoc comparison $=$ trained more than two other quadrants, right and opposite, $P<0.05)$ and platform crossings $(F=5.94, P<0.005$; Newman-Keuls post hoc comparison $=$ trained more than all other quadrants, $P<0.05$ ) (Fig. $4 \mathrm{~B}$ ). These data show that SL327 is not producing acute nonspecific effects on the animal's cognitive abilities. As an additional control, we monitored the swimming behavior of each animal during the probe trials to determine whether SL327 affected general mobility. We observed no significant difference in total path length or swim velocity between control and SL327treated mice (data not shown, $P>0.05$ ). The re-

$$
\begin{array}{lllllllllllllll}
L & E & A & R & N & I & N & G & \underset{485}{\mathbf{Q}} & M & E & M & O & R & Y
\end{array}
$$


A

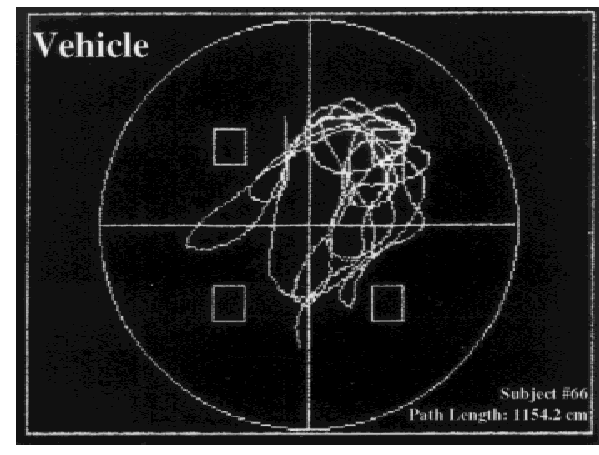

B

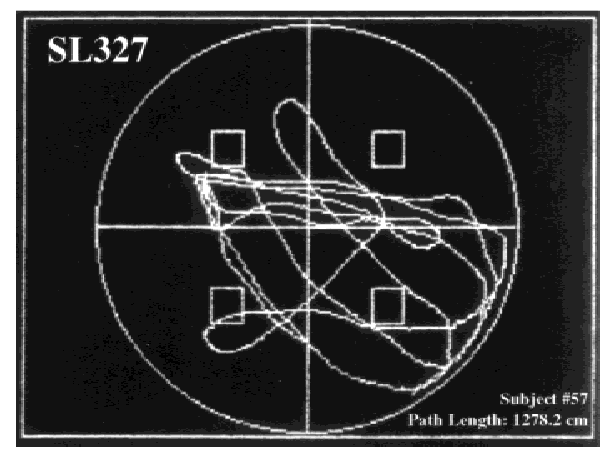

Figure 5: Mice treated with SL327 failed to exhibit a spatial strategy when searching for the platform during probe trials. A selective search strategy is one in which the subject spends significantly more time searching in the trained quadrant than in the other three quadrants. The subject must also cross the area where the platform had been during the training sessions significantly more often than they cross the corresponding areas in the other quadrants. (A) Representative probe trial of a vehicle-treated mouse. The swim path trace shown here provides an excellent example of a selective search. This particular subject was trained with the platform located in the northeast quadrant. During the probe trial, this mouse spent $56 \%$ of the time in the correct quadrant and crosses the exact area where the platform had been nine times. (B) Representative probe trial of an SL327-treated mouse. This trace does not represent a selective search. This mouse was trained with the platform in the northwest quadrant, but during the probe trial, the subject crossed this platform area only once and spent $32 \%$ of the time in this quadrant (vs. $34 \%$ in the opposite quadrant).

sults of these experiments suggest that the failure of SL327-treated animals to search selectively during the probe trials represents a learning deficit and not an impairment in the expression of a learned behavior.

The day-6 drug switch experiment also tested the role for MAPK in the maintenance of spatial memory. Although injecting SL327 before training (days 1-5) significantly impaired spatial learning compared with controls, administration of SL327 to animals that had already learned the task (day 6) had virtually no effect on performance. The lack of retrograde amnesia seen in these subjects shows that the MAPK cascade is involved in the formation and not the maintenance of spatial memories.

To control for motivational factors and perceptual and motor abilities, we tested another group of animals in the visible platform version of the Morris water maze task. The performance of mice treated with $30 \mathrm{mg} / \mathrm{kg} \mathrm{SL327}$ was not significantly different from that of vehicle-treated mice (Fig. 3B). These data suggest that the impairments seen in the hidden platform version were not due to drug effects on motivation or motor abilities.

\section{Discussion}

\section{ROLE FOR MAPK CASCADE IN LTP AND LEARNING}

A rapidly expanding body of evidence implicates the MAPK cascade in synaptic plasticity; in particular, MAPK has been shown to play a role in hippocampal LTP. Standard LTP-inducing tetanic stimulation activated the $\mathrm{p} 42$ isoform of MAPK in area CA1 of the hippocampus (English and Sweatt 1997), and pretreatment with the MEK inhibitors PD098059 (English and Sweatt 1997; Coogan et al. 1999), U0126 (Impey et al. 1998), or SL327 (Atkins et al. 1998) markedly attenuates the induction of LTP. LTP is a long-lasting, use-dependent increase in synaptic efficacy elicited by high-frequency stimulation. Both LTP and memory can be defined as persistent changes resulting from transient stimuli, and biochemical changes accompanying LTP correlate closely with those involved in learning (Atkins et al. 1998; Berman et al. 1998; Stevens 1998). The present studies are consistent with the hypothesis that LTP may represent a physiological mechanism underlying learning and memory.

Recent findings have also implicated the MAPK cascade in other forms of synaptic plasticity and learning in a variety of systems. Long-term facilitation of the sensory-motor neuron synapse in Aplysia causes translocation of MAPK into the nucleus of presynaptic neurons. Furthermore, inhibition of MAPK by either anti-MAPK antibodies or PD098059 blocks long-term, but not short-term, facilitation of the sensory-motor synapse (Martin et al. 1997; Michael et al. 1998). MAPK is also acti-

$$
\begin{array}{lllllllllllllll}
\hline & A & A & N & N & I & N & G & \mathbf{Q} & M & E & M & O & R & Y
\end{array}
$$


vated during an in vitro Pavlovian conditioning paradigm in Hermissenda, and this activation is blocked by pretreatment with PD098059 (Crow et al. 1998). Similarly, MAPK is activated in response to a novel taste, and infusion of PD098059 into the insular cortex of rats attenuates conditioned taste aversion (Berman et al. 1998).

In addition, genetic manipulations of upstream members of the cascade that leads to MAPK activation also engender learning impairments. The Drosopbila mutant leonardo lacks 14-3-3, a protein important in the activation of Raf-1 (MAPKKK) by Ras, and shows learning-related impairments (Boradie et al. 1997). Mice lacking Ras-GRF, which is a guanine-nucleotide exchange factor that induces Ras activation, display impairments in cue fear conditioning and abnormal amygdalar LTP (Brambilla et al. 1997). However, these mice show normal hippocampal function and no significant deficits in spatial learning.

\section{MAPK IN MAMMALIAN ASSOCIATIVE}

LEARNING-FEAR CONDITIONING

Our laboratory has reported recently that the MAPK cascade is also required for fear conditioning in the rat (Atkins et al. 1998), as has also been observed by Schafe et al. (1999). In the study by Atkins et al. (1998), hippocampal MAPK activation increased $1 \mathrm{hr}$ after training with a fear-conditioning protocol. This increased MAPK activation was prevented by injection of the NMDA antagonist MK801, a drug that blocks both LTP and fear conditioning (Coan et al. 1987; Bordi et al. 1996). The NMDA receptor-mediated activation of MAPK was required for learning, as inhibiting MAPK activation by intraperitoneal administration of SL327 blocked both contextual and cue learning in the rat.

As mice have become a standard genetic and behavioral model, we undertook studies on the role of MAPK in learning in mice. In the current study, SL327 injected systemically crossed the blood-brain barrier at concentrations sufficient to inhibit basal levels of MAPK activation, and could effectively eliminate contextual learning in mice as it did in rats (Atkins et al. 1998). Administration of the drug also significantly attenuated cue learning, although SL327-treated mice did display considerable freezing in response to the white noise following its pairing with a foot shock. Having shown a requirement for the MAPK cascade in contextual fear conditioning, we next investigated its role in another hippocampus-dependent task, spatial learning.

\section{SPATIAL LEARNING REQUIRES MAPK ACTIVATION}

Mice trained in the Morris water maze following administration of SL327 showed significant spatial learning deficits. Mice treated with SL327 took significantly longer to locate the escape platform during training compared with vehicle-treated controls. Furthermore, the drug-treated animals were impaired on the probe trials suggesting that SL327 impairs spatial learning performance. These results show a necessity for MAPK activation in spatial learning.

These findings are consistent with those reported in Blum et al. (1999) who reported that behavioral training in the Morris water maze increased phosphorylation of MAPK in pyramidal cells of the CA1/CA2 subfield of the dorsal hippocampus. They also showed a necessity for MAPK activation for spatial learning in rats. However, they saw an effect of PD098059 infused into the hippocampus only on the first retention trial $48 \mathrm{hr}$ after training. These differences could be due to different training or testing paradigms, species of test subjects, or differences in the efficacy and time course of MAPK inhibition by SL327 versus PD098059. One particularly intriguing possibility to explain the different observations is the locus of the drug effect. Whereas Blum et al. (1999) selectively infused a MEK inhibitor into the hippocampus, our intraperitoneal administration of SL327 inhibits MEK throughout the central nervous system. Thus, the observed differences might be accounted for by involvement of MAPK activation in extra-hippocampal areas during spatial learning.

When administered post-training, SL327 produced no impairments in water maze performance, showing that inhibition of MAPK activation had virtually no effect on the performance of animals that had already learned the water maze task. This suggests that MAPK activation is required for the formation of memory, but is unnecessary for ongoing maintenance of memory. These results are consistent with the LTP studies involving MAPK performed by English et al. (1997). In those studies, application of PD098059 before tetanization blocked the induction of LTP, but when applied 30 min after tetanization, PD098059 had no effect on the expression of established LTP.

$$
\begin{array}{lllllllllllllll}
\boldsymbol{Q} & E & A & R & N & I & N & G & M & E & M & O & R & Y \\
\mathbf{4 8 7} & & & & & &
\end{array}
$$




\section{Selcher et al.}

\section{SPECIFICITY OF SL327}

In addition to implicating MAPK in acquisition of spatial learning as opposed to maintenance, the drug treatments on training day 6 also provide a very important control showing the specificity of SL327. During this training session, the drug treatments were reversed, so that subjects that had received vehicle now received SL327 and vice versa. The fact that vehicle-trained animals showed no impairment in the Morris water maze following injection with SL327 suggests that the drug had no detrimental effects on other performance factors such as motivation or motor abilities. Basically, the drug did not produce any effects that limited the animal's ability to successfully execute the task.

Other evidence also dismissed nonspecific effects of SL327 as a possible explanation for the learning impairments seen in these tests. Control experiments confirmed that SL327 had little effect on measurements of baseline behaviors, such as general activity levels, anxiety, and pain sensitivity. However, it should be mentioned that no control was performed for tone sensitivity, allowing for the possibility that the learning impairment observed in cue conditioning was due to an effect of SL327 on sensory processing. SL327 also had no effect on a variety of other kinases, including PKA, CaMKII, and PKC, as activity levels of these protein kinases in in vitro assays were insensitive to administration of the drug. Thus, the impairments in the learning tasks seen following administration of SL327 cannot be readily attributed to nonspecific actions of the drug.

\section{DIFFERENTIAL BEHAVIORAL EFFECTS IN RATS AND MICE}

The results of the present study in mice differed somewhat from the results obtained earlier from our laboratory with rats. In the fear conditioning studies conducted in rats, 50 and $100 \mathrm{mg} / \mathrm{kg}$ SL327 were capable of completely abolishing both contextual and cue learning. SL327 also blocked contextual conditioning in the present study with mice, but cue learning proved more resistant. Although $30 \mathrm{mg} / \mathrm{kg} \mathrm{SL327}$ significantly attenuated cued freezing compared with controls, mice still exhibited marked fear in response to the tone. In fact, a more intense training paradigm, in which tone and shock are paired three times, virtually eliminates any reduction in cue learning.

This discrepancy could arise from the fact that subjects were trained with different conditioned stimuli in the two studies. In Atkins et al. (1998), rats were trained with a pure tone $(2.8 \mathrm{kHz})$, whereas in the present study, mice were exposed to white noise. The white noise may act as a stronger cue because of its wider range of frequencies. Another more interesting possible explanation is that the signal-transduction pathways leading to cue learning are different in rats and mice. In light of these findings, we must be cautious not to assume that mice will merely mimic the performance of rats in behavioral tasks.

\section{THE LOCUS OF SL327'S EFFECT}

As with any other intraperitoneal injection study, one clear caveat remains; the exact anatomical site of action of SL327 has yet to be ascertained. Therefore, it is important to note that the effects of SL327 on activation of MAPK in the hippocampus and its effect on memory formation are not necessarily causal. Evidence suggests that contextual fear conditioning is both amygdala- and hippocampus-dependent, making it difficult to determine where SL327 is acting to produce its effects (Phillips and LeDoux 1992; Kim et al. 1993). It remains unclear whether the hippocampus is the ultimate site of plasticity or whether it serves to supply the amygdala with the information necessary for forming associations between stimuli. Spatial learning, on the other hand, depends primarily on proper hippocampal function (Morris et al. 1982; Sutherland et al. 1982; Logue et al. 1997). Because this task is dependent on only the hippocampus and not the amygdala, the results from the Morris water maze suggest that SL327's effects on learning are due, at least in part, to actions in the hippocampus.

\section{MECHANISM OF ACTION}

We have shown that the MEK inhibitor SL327 impairs two learning tasks, contextual fear conditioning and the hidden platform version of the Morris water maze. Both of these tasks are hippocampus-dependent, but the responses used to assess learning in these tasks are quite different. The fact that SL327 produced similar results in the two tasks suggests that MEK inhibition truly impairs hippocampal memory formation rather than merely producing task-specific performance defects. Because of the specificity of the inhibitor used, our studies therefore show the necessity of

$$
\begin{array}{lllllllllllllll}
\hline & E & A & R & N & I & N & G & \underset{488}{\mathbf{Q}} & M & E & M & O & R & Y
\end{array}
$$


the MAPK cascade in the formation of associative and spatial memories in the mammalian nervous system.

How does MAPK activation contribute to learning and memory processes? The next step in further understanding the role of this cascade in mammalian learning requires investigating the contribution of numerous potential downstream effectors regulated by MAPK. For example, the effect on long-term facilitation in Aplysia is due in part to MAPK phosphorylation of a specific isoform of a cell-adhesion molecule (apCAM). Phosphorylation at MAPK sites leads to internalization and degradation of apCAM, lifting inhibitory constraints and allowing for synaptic reorganization (Bailey et al. 1997). MAPK has been localized both pre- and postsynaptically in the hippocampus, providing an abundant source of potential targets. These targets include synaptic vesicle proteins (Jovanovic et al. 1996), second messenger systems (Lin et al. 1993), cytoskeletal proteins (Brugg and Matus 1991), and voltage-gated ion channels such as Kv4.2 (J.P. Adams and A.E. Anderson, unpubl.).

The most attractive mechanism, however, may be linked to MAPK's role in gene expression. MAPK regulates a number of transcription factors including Elk-1 (Treisman 1996) and CREB (Impey et al. 1996, 1998; Roverson et al. 1999). In addition, MAPK appears to mediate the phosphorylation of CREB by other kinase systems such as PKA and PKC (Impey et al. 1998; Roberson et al. 1999). CREB activation produced by both forskolin and phorbol esters requires MAPK, as MEK inhibitors block the activation of CREB in area CA1 of hippocampal slices. Gaining a better understanding of the regulation of gene expression by the MAPK cascade should provide important insight into the mechanisms underlying information storage at both the synaptic and the behavioral levels.

\section{Acknowledgements}

Special thanks go to Janice L. Hytrek, A. Christine Tabaka, James S. Piecara, and Christopher A. Teleha of DuPont Pharmaceuticals for synthesis of SL327. This work was supported by the National Institutes of Health (J.D.S., MH 57014) and a NARSAD Independent Investigator Award (J.D.S.).

The publication costs of this article were defrayed in part by payment of page charges. This article must therefore be hereby marked "advertisement" in accordance with 18 USC section 1734 solely to indicate this fact.

\section{References}

Abeliovich, A., R. Paylor, C. Chen, J.J. Kim, J.M. Wehner, and S. Tonegawa. 1993. PKC $\gamma$ mutant mice exhibit mild deficits in spatial and contextual learning. Cell 75: 1263-1271.

Atkins, C.M., J.C. Selcher, J.J. Petraitis, J.M. Trazskos, and J.D. Sweatt. 1998. The MAPK cascade is required for mammalian associative learning. Nat. Neurosci. 1: 602-607.

Bailey, C.H., B.-K. Kaang, M. Chen, K.C. Martin, C.S. Lim, A. Casadio, and E.R. Kandel. 1997. Mutation in the phosphorylation sites of MAP kinase blocks learning-related internalization of apCAM in Aplysia sensory neurons. Neuron 18: $913-924$.

Berman, D.E., S. Hazvi, K. Rosenblum, R. Seger, and Y. Dudai. 1998. Specific and differential activation of mitogen-activated protein kinase cascades by unfamiliar taste in the insular cortex of the behaving rat. J. Neurosci. 18: 10037-10044.

Blum, S., A.N. Moore, F. Adams, and P.K. Dash. 1999. A mitogen-activated protein kinase cascade in the CA1/CA2 subfield of the dorsal hippocampus is essential for long-term spatial memory. J. Neurosci. 19: 3535-3544.

Bordi, F., C. Marcon, C. Chiamulera, and A. Reggiani. 1996. Effects of the metabotropic glutamate receptor antagonist MCPG on spatial and context-specific learning. Neuropharmacology 35: 1557-1565.

Bourtchuladze, R., B. Frenguelli, J. Blendy, D. Cioff G. Schutz, and A.J. Silva. 1994. Deficient long-term memory in mice with a targeted mutation of the cAMP-reponsive element-binding protein. Cell 79: 59-68.

Brambilla, R., N. Gnesutta, L. Minichiello, G. White, A.J. Roylance, C.E. Herron, M. Ramsey, D.P. Wolfer, V. Cestari, C. Rossi-Arnaud, S.G.N. Grant, P.F. Chapman, H.-P. Lipp, E. Sturani, and R. Klein. 1997. A role for the Ras signalling pathway in synaptic transmission and long-term memory. Nature 390: 281-286.

Broadie, K., E. Rushton, E.M. Skoulakis, and R.L. Davis. 1997. Leonardo, a Drosophila 14-3-3 protein involved in learning, regulates presynaptic function. Neuron 19: $391-402$.

Brugg, B. and A. Matus. 1991. Phosphorylation determines the binding of microtubule-associated protein 2 (MAP2) to microtubules in living cells. J. Cell Biol. 114: 735-743.

Chen, S.-J., E. Klann, M.C. Gower, C.M. Powell, J.S. Sessoms, and J.D. Sweatt. 1993. Studies with synthetic peptide substrates derived from the neuronal protein neurogranin revel structural determinants of potency and selectivity for protein kinase C. Biochemistry 32: 1032-1039.

Coan, E.J., W. Saywood, and G.L. Collingridge. 1987. MK-801 blocks NMDA receptor-mediated synaptic transmission and long term potentiation in rat hippocampal slices. Neurosci. Lett. 80: 111-114.

Coogan, A.N., D.M. O'Leary, and J.J. O'Connor. 1999. P42/44 MAP kinase inhibitor PD98059 attenuates multiple forms of synaptic plasticity in rat dentate gyrus in vitro. J. Neurophysiol. 81: 103-110.

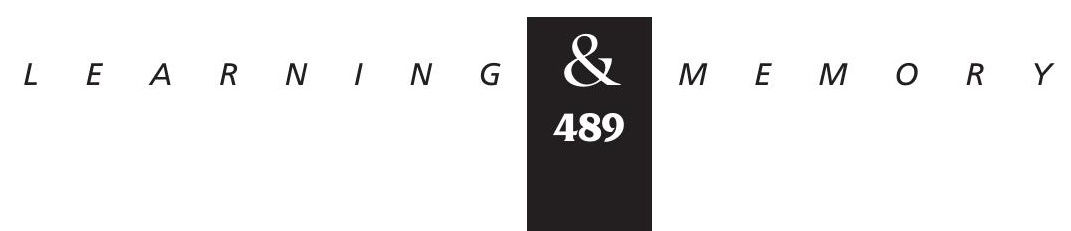




\section{Selcher et al.}

Crow, T., J.-J. Xue-Bian, V. Siddiqi, T. Kang, and J.T. Neary. 1998. Phosphorylation of mitogen-activated protein kinase by one-trial and multi-trial classical conditioning. J. Neurosci. 18: $3480-3487$.

English, J.D. and J.D. Sweatt. 1996. Activation of p42 mitogen-activated protein kinase in hippocampal long-term potentiation. J. Biol. Chem. 271: 24329-24332.

1997. A requirement for the mitogen-activated protein kinase cascade in hippocampal long-term potentiation. J. Biol. Chem. 272: 19103-19106.

Favata, M.F., K.Y. Horiuchi, E.J. Manos, A.J. Daulerio, D.A. Stradly, W.S. Feeser, D.E. Van Dyk, W.J. Pitts, R.A. Earl, F. Hobbs, R.A. Copeland, R.L. Magolda, P.A. Scherle, and J.M. Trzaskos. 1998. Identification of a novel inhibitor of mitogen-activated protein kinase kinase. J. Biol. Chem. 273: 18623-18632.

Impey, S., M. Mark, E.C. Villacres, S. Poser, C. Chavkin, and D.R. Storm. 1996. Induction of CRE-mediated gene expression by stimuli that generate long-lasting LTP in area CA1 of the hippocampus. Neuron 16: 973-982.

Impey, S., K. Obrietan, S.T. Wong, S. Poser, S. Yano, G. Wayman, J.C. Deloulme, G. Chan, and D.R. Storm. 1998. Cross talk between ERK and PKA is required for $\mathrm{Ca}^{2+}$ stimulation of CREB-dependent transcription and ERK nuclear translocation. Neuron 21: 869-883.

Jovanovic, J.N., F. Benfenati, Y.L. Siow, T.S. Sihra, J.S. Sanghera, S.L. Pelech, P. Greengard, and A.J. Cazernik. 1996. Neurotrophins stimulate phosphorylation of synapsin I by MAP kinase and regulate synapsin I-actin interactions. Proc. Natl. Acad. Sci. 93: 3679-3683.

Kim, J.J., R.A. Rison, and M.S. Fanselow. 1993. Effects of amygdala, hippocampus, and periaqueductal gray lesions on short- and long-term contextual fear. Behav. Neurosci. 107: 1093-1098.

LeDoux, J.E. 1995. Emotion: Clues from the brain. Annu. Rev. Psychol. 46: 209-235.

Lin, L.-L., M. Wartmann, A.Y. Lin, J.L. Knopf, A. Seth, and R.J. Davis. 1993. CPLA ${ }_{2}$ is phosphorylated and activated by MAP kinase. Cell 72: 269-278.

Logue, S.F., R. Paylor, and J.M. Wehner. 1997. Hippocampal lesions cause learning deficits in inbred mice in the Morris water maze and conditioned-fear task. Behav. Neurosci. 111: 104-113.

Mansuy, I.M., D.G. Winder, T.M. Moallem, M. Osman, M. Mayford, R.D. Hawkins, and E.R. Kandel. 1998. Inducible and reversible gene expression with the rtTA system for the study of memory. Neuron 21: 257-265.

Martin, K.C., D. Michael, J.C. Rose, M. Barad, A. Casadio, H. Zhu, and E.R. Kandel. 1997. MAP kinase translocates into the nucleus of the presynaptic cell and is required for long-term facilitation in Aplysia. Neuron 18: 899-912.
Michael, D., K.C. Martin, R. Seger, M.-M. Ning, R. Baston, and E.R. Kandel. 1998. Repeated pulses of serotonin required for long-term facilitation activate mitogen-activated protein kinase in sensory neurons of Aplysia. Proc. Natl. Acad. Sci. 95: 1864-1869.

Morris, R.G.M. 1981. Spatial localisation does not depend on the presence of local cues. Learn. Motiv. 12: 239-260.

Morris, R.G.M., P. Garrud, J.N.P. Rawlins, and J. O'Keefe. 1982. Place navigation impaired in rats with hippocampal lesions. Nature 297: 681-683.

Nogues, X., R. Jaffard, and J. Micheau. 1996. Investigations on the role of hippocampal protein kinase $C$ on memory processes: Pharmacological approach. Behav. Brain Res. 75: 139-146.

Paylor, R., L. Baskall-Baldini, L. Yuva, and J.M. Wehner. 1996. Developmental differences in place-learning performance between $\mathrm{C} 57 \mathrm{BL} / 6$ and $\mathrm{DBA} / 2$ mice parallel the ontogeny of hippocampal protein kinase C. Behav. Neurosci. 110: $1415-1425$

Phillips, R.G. and J.E. LeDoux. 1992. Differential contribution of amygdala and hippocampus to cued and contextual fear conditioning. Behav. Neurosci. 106: 274-285.

Roberson, E.D., J.D. English, J.P. Adams, J.C. Selcher, C. Kondratick, and J.D. Sweatt. 1999. The mitogen-activated protein kinase cascade couples PKA and PKC to CREB phosphorylation in area CA1 of the hippocampus. J. Neurosci. 19: 4337-4348.

Schafe, G.E., N.V. Nadel, G.M. Sullivan, A. Harris, and J.E. LeDoux. 1999. Memory consolidation for contextual and auditory fear conditioning is dependent on protein synthesis, PKA, and MAP kinase. Learn. \& Mem. 6: 97-110.

Seger, R. and E.G. Krebs. 1995. The MAPK signaling cascade. FASEB J. 9: 726-735.

Silva, A.J., R. Paylor, J.M. Wehner, and S. Tonegawa. 1992. Impaired spatial learning in $\alpha$-calcium-calmodulin kinase II mutant mice. Science 257: 206-211.

Stevens, C.F. 1998. A million dollar question: Does LTP = memory? Neuron 20: 1-2.

Sutherland, R.J., B. Kolb, and I.Q. Whishaw. 1982. Spatial mapping: Definitive distruption by hippocampal or medial frontal cortical damage in the rat. Neurosci. Lett. 31: $271-276$

Treisman, R. 1996. Regulation of transcription by MAP Kinase cascades. Curr. Opin. Cell Biol. 8: 205-215.

Wolfman, C., C. Fin, M. Dias, M. Bianchin, R.C. Da Silva, P.K. Schmitz, J.H. Medina, and I. Izquierdo. 1994. Intrahippocampal or intraamygdala infusion of KN62, a specific inhibitor of calcium/calmodulin-dependent protein kinase II, causes retrograde amnesia in the rat. Behav. Neural Biol. 61: 203-205.

Received June 25, 1999; accepted in revised form August 20, 1999.

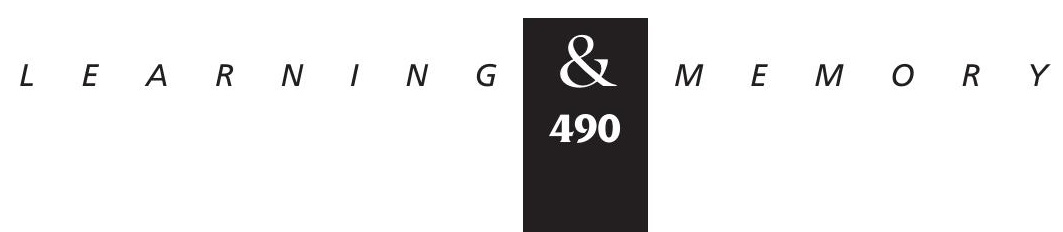




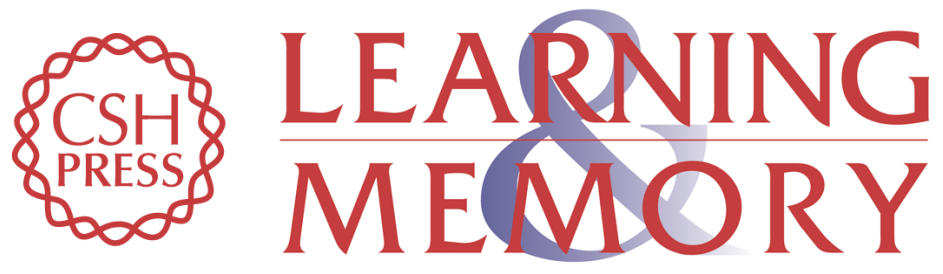

\section{A Necessity for MAP Kinase Activation in Mammalian Spatial Learning}

Joel C. Selcher, Coleen M. Atkins, James M. Trzaskos, et al.

Learn. Mem. 1999, 6:

Access the most recent version at doi:10.1101//m.6.5.478

References This article cites 40 articles, 12 of which can be accessed free at: http://learnmem.cshlp.org/content/6/5/478.full.html\#ref-list-1

License

Email Alerting Receive free email alerts when new articles cite this article - sign up in the box at the Service top right corner of the article or click here. 